Original article

\title{
COVID-19 pandemic and its average recovery time in Indian states
}

\author{
Noel George *, Naresh K. Tyagi, Jang Bahadur Prasad \\ Department of Epidemiology and Biostatistics, KAHER, Belagavi, 590010, Karnataka, India
}

\section{A R T I C L E I N F O}

\section{Keywords:}

COVID-19

Recovery time

Models

Indian states

Degree polynomials

\begin{abstract}
A B S T R A C T
Background: Many studies have been carried out in modelling COVID-19 pandemic. However, region-wise average duration of recovery from COVID-19 has not been attempted; hence, an effort has been made to estimate state-wise recovery duration of India's COVID-19 patients. Determining the recovery time in each region is intended to assist healthcare professionals in providing better care and planning of logistics.

Methods: This study used database provided by Kaggle, which takes data from the Ministry of Health \& Family Welfare. The simple Linear Regression model between incidence, prevalence, and duration was used to assess the duration of COVID-19 disease in various Indian states.

Results: The fitted model suits ideal for most of the states, except for some union territories and northeastern states. The average time to recover from disease was ranging from 5 to 36 days in Indian states/union territories except for Madhya Pradesh. Tamil Nadu has an average recovery time of 7 days with an value of 0.96 , followed by Odisha, Karnataka, West Bengal, Kerala and Chhattisgarh and the average recovery duration was estimated as 7, 13, 17, 11, 14 and 12 days respectively.

Conclusion: The average recovery from COVID-19 was ten or less days in twenty percentage of states, whereas in forty-four percentage of states/union territories had an average recovery duration between ten to twenty days. However, around twentyfour percentage of states/union territory recovered between twenty to thirty days. In the rest of Indian states/union territories, the average duration of recovery was more than thirty days.
\end{abstract}

\section{Introduction}

The COVID-19 was a human tragedy infecting around 99.86 million individuals, resulting in around 2.1 million deaths by January 27, 2021. India recorded the first case of COVID-19 on January 30, 2020, and cases increased steadily to hit about 10.68 million cases and 153,724 deaths by January 27, 2021. Factors like the stage of disease at admission, patient's care and so forth sway the average COVID recovery duration explicitly. The Ministry of Health has released home isolation guidelines (April 7, 2020) for very mild and pre-symptomatic COVID-19 cases to remain at home quarantine. ${ }^{1}$ Furthermore, the Government and hospital's policy in admitting patients are expected to significantly influence the actual recovery duration. ${ }^{7}$ According to the World Health Organisation, an act of violence related to the COVID-19 pandemic takes place due to the social stigma and discriminatory behaviours against anyone perceived to have been in contact with the virus or affected by the disease. A similar fear in the community of getting admitted to a hospital and the healthcare workers' behaviour towards the COVID-19 patients also act as possible factors in affecting the average duration. As per the reports by The Lancet (2020), some Indian states had not recorded any suspected case, or probable COVID-19 deaths may also alter the recovery duration of COVID cases. ${ }^{14}$ The improper follow-ups of patients, sensitivity and specificity of the diagnostic tests are other possible factors affecting the average duration of disease.

The incubation period of COVID-19 has been reported as 14 days with a $95 \%$ confidence interval of $8-16$ days. $^{2}$ If the incidence of a disease is very high, and the recovery time of the disease is also high, then the prevalence of the disease increases, which puts extra health, economic and social burden on the country's economy. ${ }^{12}$ A piolet study conducted in India by Barman MP et al. (2020) on 221 COVID patients found that the probability of recovery from COVID-19 in 10 days is minimal; only $4 \%$ of the patients recovered in 10 days, and about $40 \%$ of the patients in 20 days. In 25 days of treatment, about $50 \%$ of the patients were discharged from the hospital. The study also concluded that the average recovery duration of COVID-19 patients in India had been found 25 days, with a $95 \%$ confidence interval of 16 days- 34 days. ${ }^{9}$ The average duration of COVID-19 is generally computed from hospital-based studies rather than from the community. Therefore, the

\footnotetext{
* Corresponding author.

E-mail addresses: noelgeorge2007@gmail.com (N. George), nareshktyagi@gmail.com (N.K. Tyagi), jbiips12@gmail.com (J.B. Prasad).
} 
present study has been planned to determine the average duration of COVID-19 patients from the community.

Many studies have been carried out to model the COVID-19 pandemic in India; however, there are only a few peer-reviewed articles on the recovery period of patients with COVID-19 where the period of a patient in disease has been assessed. Knowledge of the average duration of recovery time helps the Government to prepare effective measures for the healthcare system. ${ }^{9}$ Determining the average duration of recovery time from COVID-19 in each region is expected to help the health professionals for better treatment and arrangement of logistics. Hence, an effort has been made to estimate the recovery duration of India's COVID-19 patients for each state which intern expected to establish a social and economic initiative to help COVID-19 patients during the disease period and thereafter.

\section{Methods \& materials}

This study has used an open-source database provided by Kaggle, which takes the data from the Ministry of Health \& Family Welfare, Government of India. A statistical model was developed to study the duration of patients in COVID-19 for each state of India. Data was taken directly from the first day of reporting for each state. During data cleaning and checking for duplicates, Telangana was removed from the analysis due to the inappropriateness of the reported data. The complete data of Tripura was also not available in the dataset.

The standard relationship between Incidence \& Prevalence ${ }^{10,11,13}$ :

Prevalence $=$ Incidence $*$ Duration

Duration $=\frac{\text { Prevalence }}{\text { Incidence }}=\frac{\frac{\text { Active Cases }}{\text { Exposed Poplation }}}{\frac{\text { New Cases }}{\text { Exposed population }}}$

Duration of disease $=\frac{\text { Active Cases of COVID }-19}{\text { New Cases of COVID }-19}$

The models to estimate the Active Cases on $\mathrm{i}^{\text {th }}$ day was:

$\widehat{Y}=\mathrm{Ae}^{\mathrm{a}_{1} \mathrm{t}+\mathrm{a}_{2} \mathrm{t}^{2}}$ and $\widehat{\mathrm{Y}}=\mathrm{Be}^{\mathrm{b}_{1} \mathrm{t}+\mathrm{b}_{2} t^{2}+\mathrm{b}_{3} t^{3}}$

where, $\mathrm{A}=\mathrm{e}^{\mathrm{a}_{0}}, \mathrm{~B}=\mathrm{e}^{\mathrm{b}_{0}}$ and $\mathrm{a}_{0}, \mathrm{a}_{1}, \mathrm{a}_{2}$, and $\mathrm{b}_{0}, \mathrm{~b}_{1}, \mathrm{~b}_{2}$ and $\mathrm{b}_{3}$ are the Regression Coefficients.

95\% Confidence Interval (CI) of predicted active cases on each day was computed as:

$95 \% \mathrm{CI}=e^{\text {Predicted Number oflog( Active Cases }) \pm 1.96 * \mathrm{SE}(\text { Predicted number of } \log (\text { Active Cases }))}$

$95 \% \mathrm{CI}=e^{\mathrm{Ae}^{\mathrm{a}_{1} \mathrm{t}+\mathrm{a}_{2} t^{2}} \pm 1.96 * \mathrm{sqrt}\left(\frac{1}{\mathrm{a}}+\frac{1}{\mathrm{~b}}+\frac{1}{\mathrm{c}}+\frac{1}{\mathrm{~d}}\right)}$

where, S.E. for Quadratic model was computed as:

S.E.(Predicted Number of Active Cases at $x_{i}$ day) $=$ S.D. $\sqrt{\frac{1}{n}+\frac{\left(x_{i}-\bar{x}\right)^{2}}{\sum\left(x_{i}-\bar{x}\right)^{2}}}$

$$
+\frac{\left(\mathrm{x}_{\mathrm{i}}^{2}-\bar{x}^{2}\right)^{2}}{\sum\left(\mathrm{x}_{\mathrm{i}}^{2}-\overline{\mathrm{x}}^{2}\right)^{2}}
$$

where S.D. is the Standard Deviation of y, which is calculated as:

S.D. $=\sqrt{\frac{\sum(\mathrm{y}-\widehat{\mathrm{y}})^{2}}{\mathrm{n}-1}}$

where, $\mathrm{y}$ is the log transformation of seven days moving average of Total Active Cases, $\hat{y}$ is the predicted number of the Active Cases, and ' $n$ ' is the number of days Active Cases were observed. The coefficient of determination $\left(R^{2}\right)$ is evaluated to assess the good fit of the model. The entire

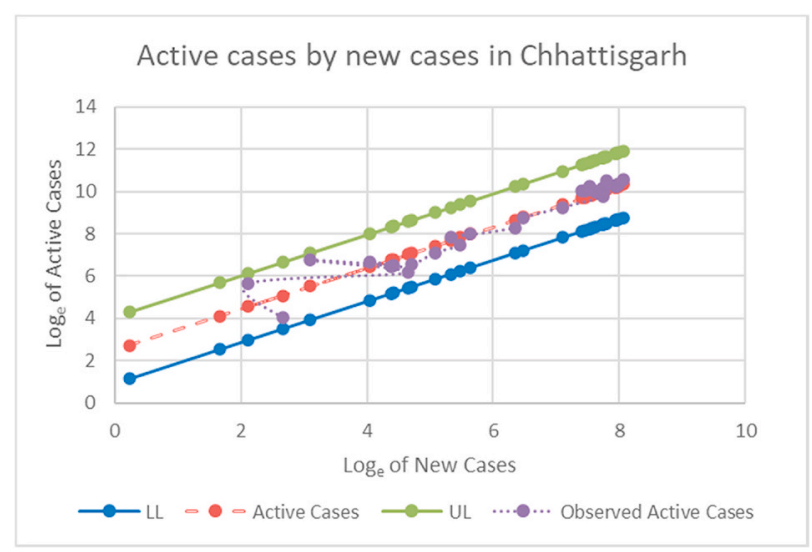

Fig. 1. Active cases by new cases in Chhattisgarh

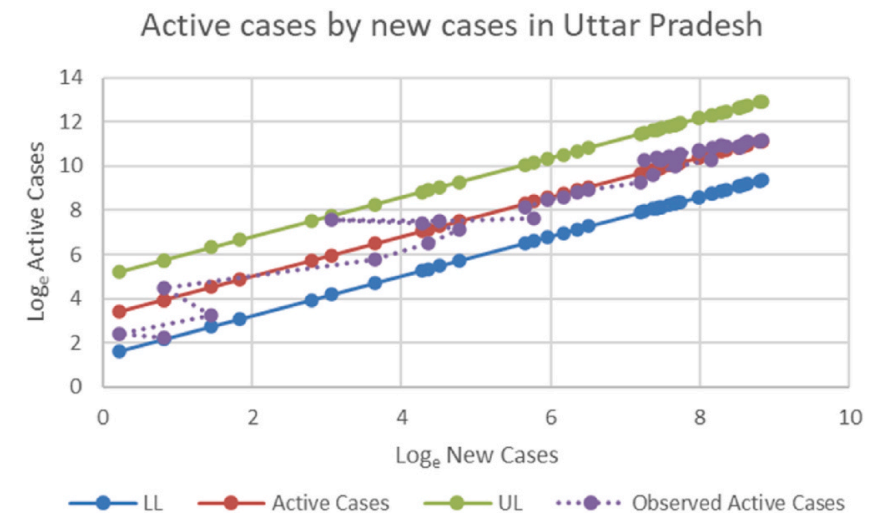

Fig. 2. Active cases by new cases in Uttar Pradesh

discussion and result section will be based on six regions in accordance with The National Family Health Survey (NFHS) division.

\section{Results}

The prediction model was performed with respect to each state. Histogram for the standardized residual of the fitted regression model with $\log$ of active cases as dependent variable looked plausible where residuals approximated a normal distribution with no weird shapes or low values or extremely high values. Normal P-P plot demonstrated that the distribution of standardized residual deviates only moderately from a distribution that was classically bell-shaped. The scatter plot indicated that the distribution of residuals across the expected values was equal,

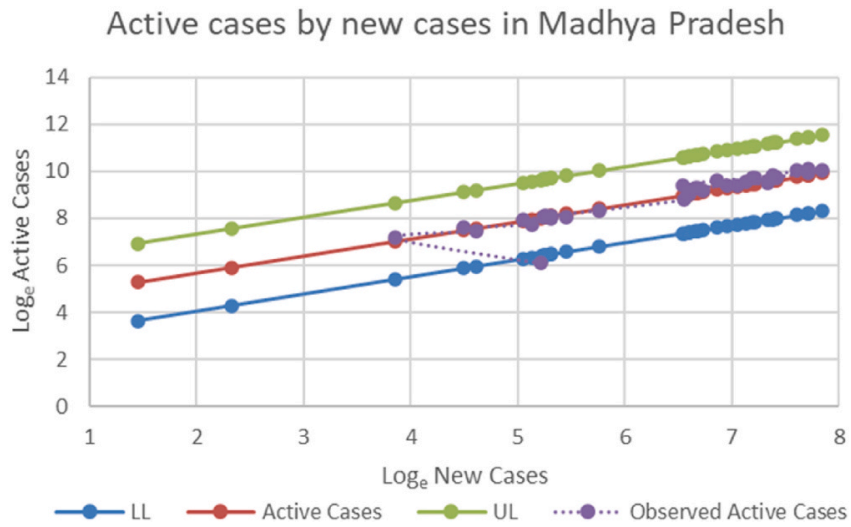

Fig. 3. Active cases by new cases in Madhya Pradesh 
Table 1

Average recovery duration in days of COVID-19 patients in Indian states.

\begin{tabular}{|c|c|c|c|c|c|c|c|c|}
\hline Region & State & R Square & F Statistic & B & $\mathrm{b}_{1}$ & Average Duration (Days) & Lower Limit & Upper limit \\
\hline \multirow[t]{3}{*}{ Central } & Chhattisgarh & 0.941 & 4184.161 & 2.511 & 0.969 & 12.319 & 10.406 & 14.583 \\
\hline & Uttar Pradesh & 0.883 & 2101.031 & 3.222 & 0.896 & 25.073 & 19.353 & 32.484 \\
\hline & Madhya Pradesh & 0.761 & 835.595 & 4.225 & 0.726 & 68.360 & 50.348 & 92.814 \\
\hline \multirow[t]{4}{*}{ East } & Odisha & 0.956 & 5823.254 & 2.562 & 0.940 & 12.958 & 11.168 & 15.035 \\
\hline & West Bengal & 0.948 & 4789.756 & 2.441 & 0.980 & 11.482 & 9.497 & 13.881 \\
\hline & Bihar & 0.923 & 3143.014 & 2.808 & 0.914 & 16.569 & 13.637 & 20.132 \\
\hline & Jharkhand & 0.871 & 1695.179 & 3.204 & 0.867 & 24.631 & 19.806 & 30.632 \\
\hline \multirow[t]{9}{*}{ North } & Rajasthan & 0.937 & 4179.219 & 2.650 & 0.952 & 14.157 & 11.801 & 16.984 \\
\hline & Jammu and Kashmir & 0.932 & 3737.557 & 2.604 & 1.007 & 13.518 & 11.337 & 16.118 \\
\hline & Himachal Pradesh & 0.915 & 2802.949 & 2.914 & 0.898 & 18.424 & 15.930 & 21.309 \\
\hline & Uttarakhand & 0.901 & 2441.060 & 2.986 & 0.899 & 19.815 & 16.625 & 23.616 \\
\hline & Haryana & 0.891 & 2274.574 & 3.440 & 0.806 & 31.181 & 25.567 & 38.029 \\
\hline & Delhi & 0.870 & 1884.836 & 3.123 & 0.892 & 22.704 & 17.157 & 30.043 \\
\hline & Punjab & 0.802 & 1112.494 & 3.609 & 0.811 & 36.918 & 28.370 & 48.042 \\
\hline & Chandigarh & 0.789 & 986.271 & 3.457 & 0.740 & 31.725 & 26.839 & 37.502 \\
\hline & Ladakh & 0.750 & 829.768 & 3.337 & 0.806 & 28.140 & 23.760 & 33.327 \\
\hline \multirow[t]{7}{*}{ Northeast } & Manipur & 0.936 & 3776.925 & 1.598 & 1.224 & 4.943 & 4.213 & 5.800 \\
\hline & Arunachal Pradesh & 0.863 & 1568.943 & 1.838 & 1.193 & 6.283 & 5.073 & 7.783 \\
\hline & Meghalaya & 0.856 & 1414.242 & 3.140 & 0.878 & 23.105 & 19.702 & 27.097 \\
\hline & Assam & 0.850 & 1423.111 & 3.540 & 0.842 & 34.464 & 26.671 & 44.534 \\
\hline & Nagaland & 0.671 & 417.574 & 2.869 & 0.980 & 17.625 & 12.427 & 24.999 \\
\hline & Sikkim & 0.669 & 401.005 & 3.353 & 0.754 & 28.580 & 22.841 & 35.760 \\
\hline & Mizoram & 0.588 & 368.827 & 2.743 & 0.955 & 15.540 & 12.208 & 19.782 \\
\hline \multirow[t]{7}{*}{ South } & Tamil Nadu & 0.967 & 8117.149 & 1.911 & 1.061 & 6.758 & 5.710 & 7.999 \\
\hline & Karnataka & 0.950 & 5227.651 & 2.804 & 0.968 & 16.514 & 13.753 & 19.829 \\
\hline & Kerala & 0.946 & 5514.687 & 2.629 & 0.966 & 13.861 & 11.882 & 16.170 \\
\hline & Andhra Pradesh & 0.898 & 2381.962 & 2.940 & 0.926 & 18.909 & 14.610 & 24.472 \\
\hline & Telangana & 0.840 & 2767.206 & 2.936 & 0.935 & 18.836 & 15.647 & 22.675 \\
\hline & Puducherry & 0.826 & 1257.392 & 3.133 & 0.878 & 22.945 & 18.743 & 28.089 \\
\hline & Andaman and Nicobar Islands & 0.804 & 1052.745 & 1.967 & 1.139 & 7.150 & 5.993 & 8.530 \\
\hline \multirow[t]{4}{*}{ West } & Gujarat & 0.920 & 3043.271 & 2.251 & 1.056 & 9.494 & 7.450 & 12.098 \\
\hline & Goa & 0.884 & 1949.522 & 2.036 & 1.064 & 7.664 & 6.167 & 9.524 \\
\hline & Maharashtra & 0.864 & 1746.580 & 3.102 & 0.965 & 22.240 & 15.389 & 32.142 \\
\hline & Dadra, Nagar Haveli, Daman and Diu & 0.732 & 593.038 & 2.688 & 0.835 & 14.699 & 12.449 & 17.355 \\
\hline
\end{tabular}

$\mathrm{p}$ value is $<0.05$ for all states, $\mathrm{B}=$ unstandardized beta coefficient, b1 = slop of the regression line.

Active cases by new cases in Odisha

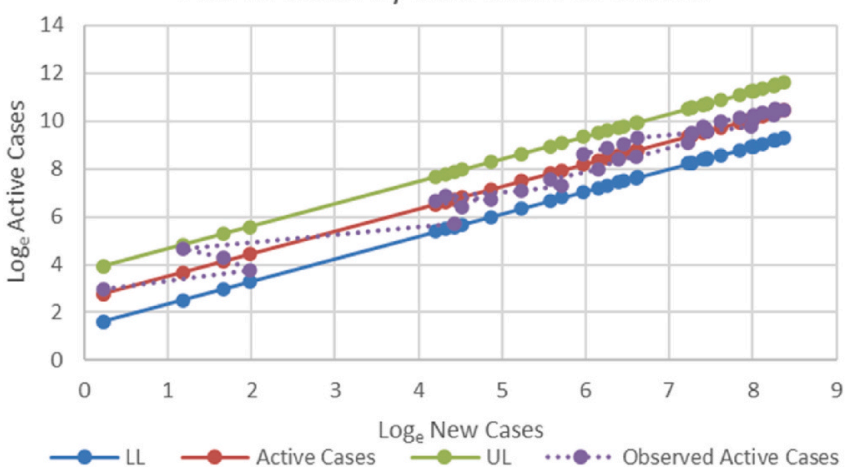

Fig. 4. Active cases by new cases in Odisha

suggesting that the model was homoscedastic. Statistical models have been constructed for the duration of patients under COVID-19 across all states in India. The model fitted well for all the regions. Log of new cases and $\log$ of observed cases were plotted against the log of predicted active cases with the corresponding upper and lower confidence limits.

\subsection{Central region}

Log of new cases was plotted against log of predicted active cases with the corresponding upper and lower confidence limits and was found linear for central states of India comprising the states Chhattisgarh, Uttar Pradesh, and Madhya Pradesh (Figs. 1-3). Even though the model fit was enough to predict the average duration of COVID-19, there was a significant difference in the average duration between central

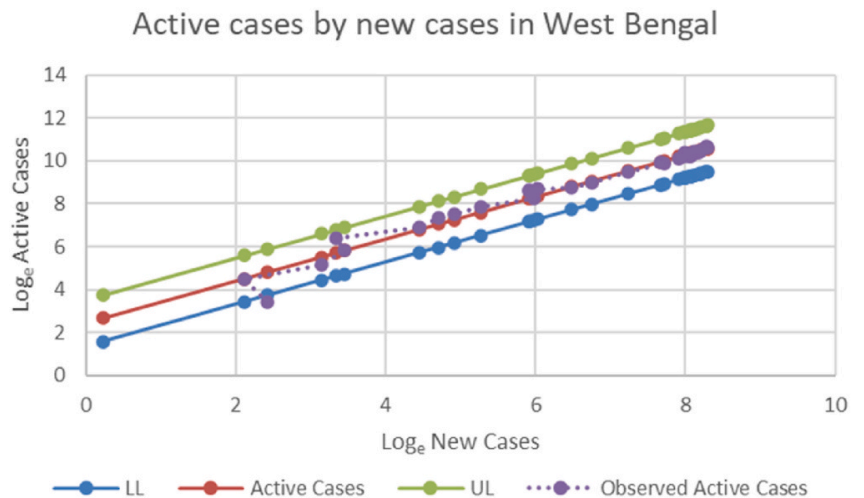

Fig. 5. Active cases by new cases in West Bengal

states. Madhya Pradesh $\left(\mathrm{R}^{2}=0.76\right)$ has an average duration as high as 68 days $(C I=50.348-92.814)$, whereas Uttar Pradesh $\left(R^{2}=0.88\right)$ with 25 days $(C I=19.35-32.48)$ and Chhattisgarh $\left(R^{2}=0.94\right)$ with 12 days $(C I$ $=10.40-14.58)$ (Table 1).

\subsection{Eastern region}

Log of new cases against log of predicted active cases was plotted for Odisha, West Bengal, Bihar, and Jharkhand (Figs. 4-7). The average duration in days where a patient remains infected is identified as 11 days $(C I=9.49-13.88)$ in the state of West Bengal $\left(R^{2}=0.94\right)$, while the average days increased to 25 days $(\mathrm{CI}=19.80-30.63)$ in Jharkhand $\left(\mathrm{R}^{2}\right.$ $=0.87)$. Duration of disease in Odisha $\left(\mathrm{R}^{2}=0.95\right)$ and $\operatorname{Bihar}\left(\mathrm{R}^{2}=0.92\right)$ are 13 days $(\mathrm{CI}=11.16-15.03)$ and 17 days $(\mathrm{CI}=13.63-20.13)$ 
Active cases by new cases in Bihar

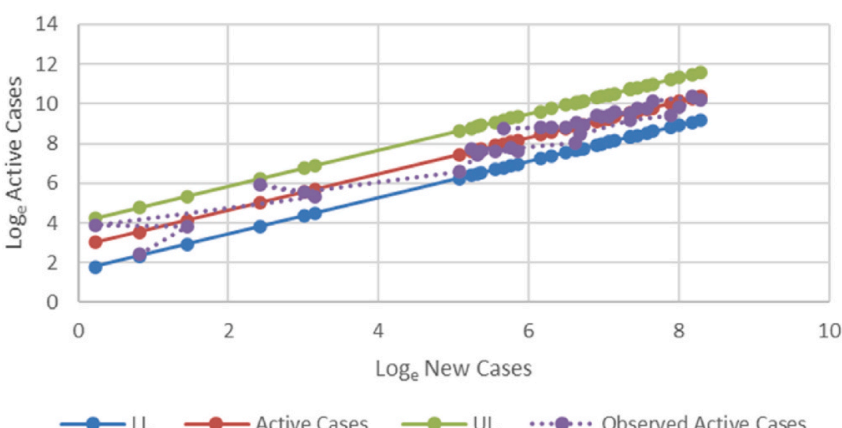

Fig. 6. Active cases by new cases in Bihar

Active cases by new cases in Jharkhand

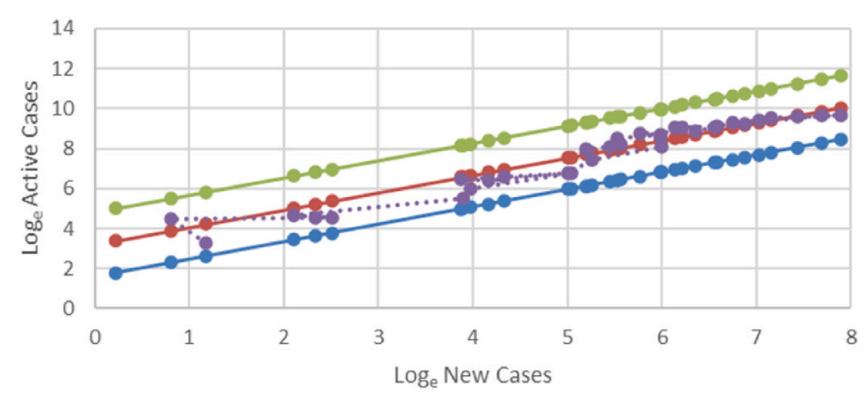

$\longrightarrow \mathrm{LL} \longrightarrow$ —Active Cases $\longrightarrow$ UL $\quad \cdots \bullet \cdot$.. Observed Active Cases

Fig. 7. Active cases by new cases in Jharkhand

Active cases by new cases in Rajasthan

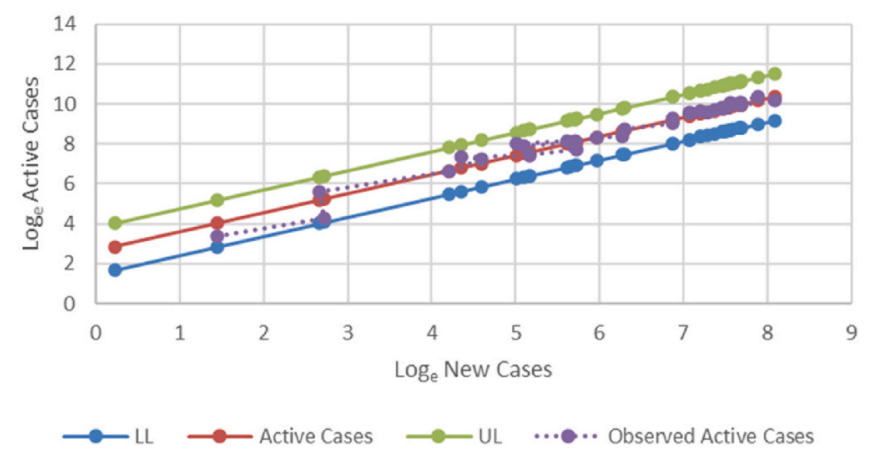

Fig. 8. Active cases by new cases in Rajasthan

Active cases by new cases in Jammu and Kashmir

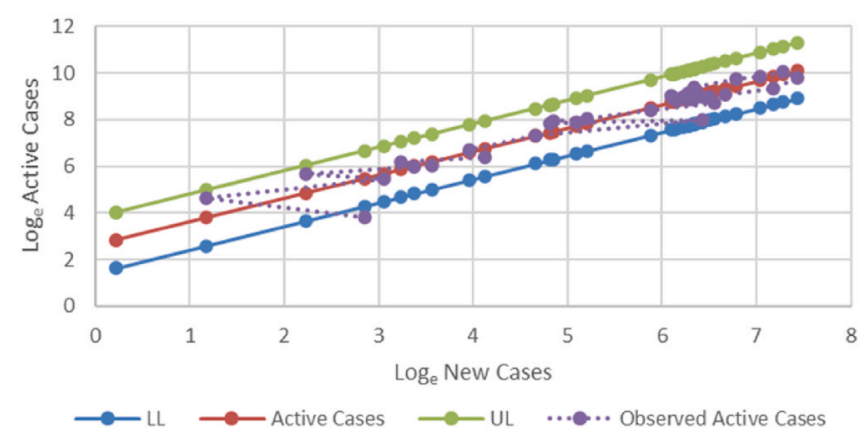

Fig. 9. Active cases by new cases in Jammu and Kasmir
Active cases by new cases in Himachal Pradesh

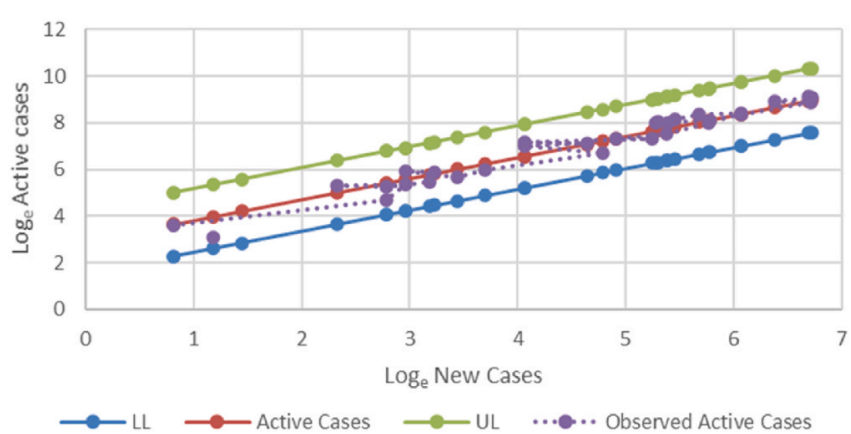

Fig. 10. Active cases by new cases in Himachal Pradesh

Active cases by new cases in Uttarakhand

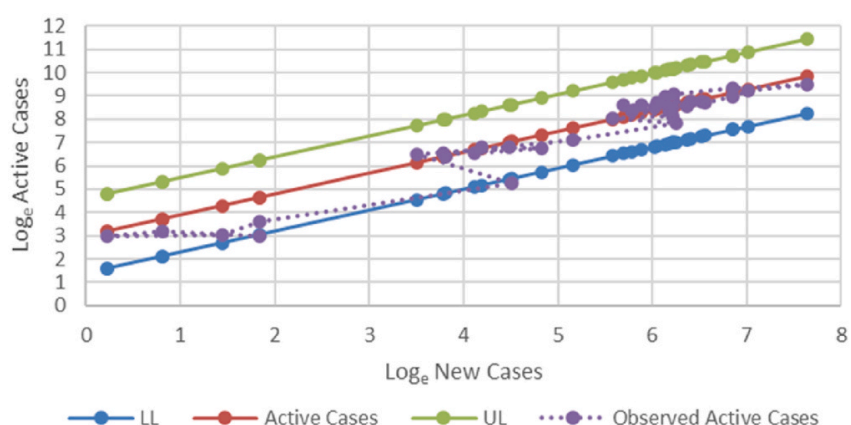

Fig. 11. Active cases by new cases in Uttarakhand

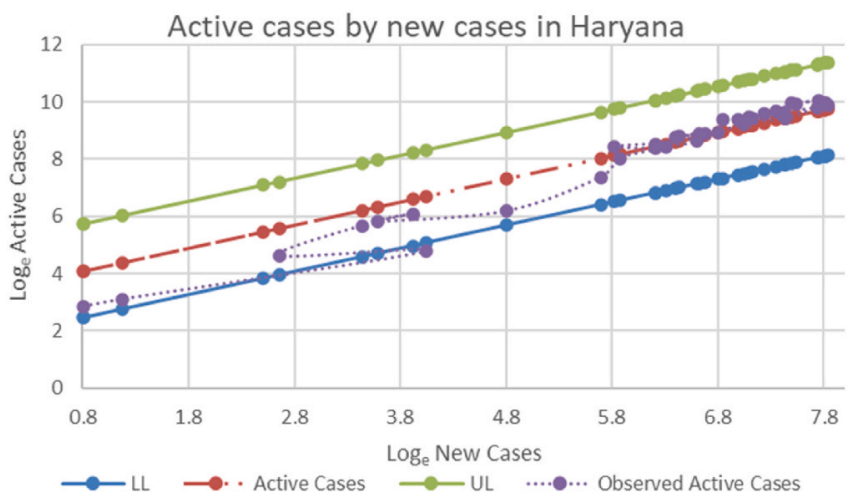

Fig. 12. Active cases by new cases in Haryana

Active cases by new cases in Delhi

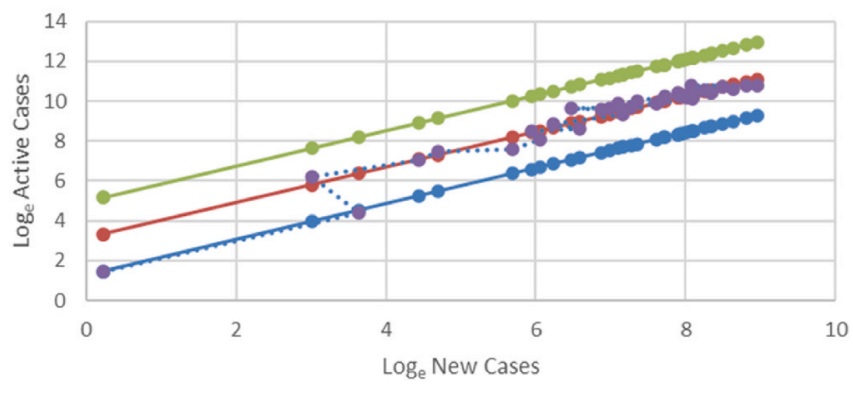

$\longrightarrow$ LL $\longrightarrow$ Active Cases $\longrightarrow$ UL $\quad$..... Observed Active Cases

Fig. 13. Active cases by new cases in Delhi 
Active cases by new cases in Punjab

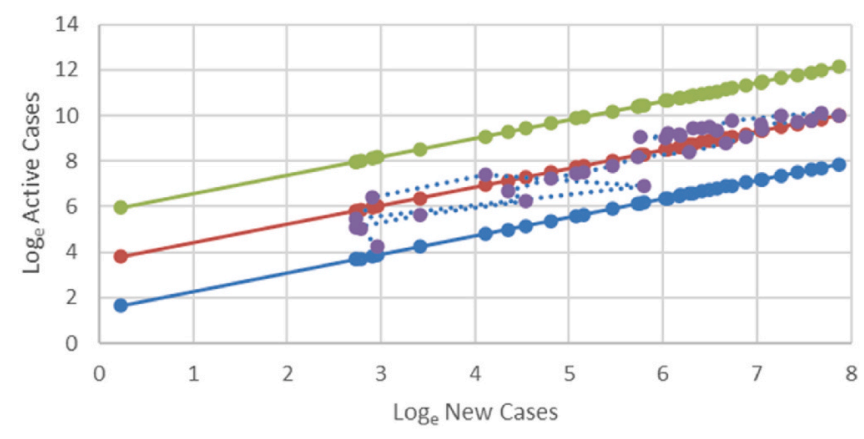

$\multimap$ LL —-Active Cases $\multimap-U L \quad \cdots \bullet .$. Observed Active Cases

Fig. 14. Active cases by new cases in Punjab

Active cases by new cases in Chandigarh

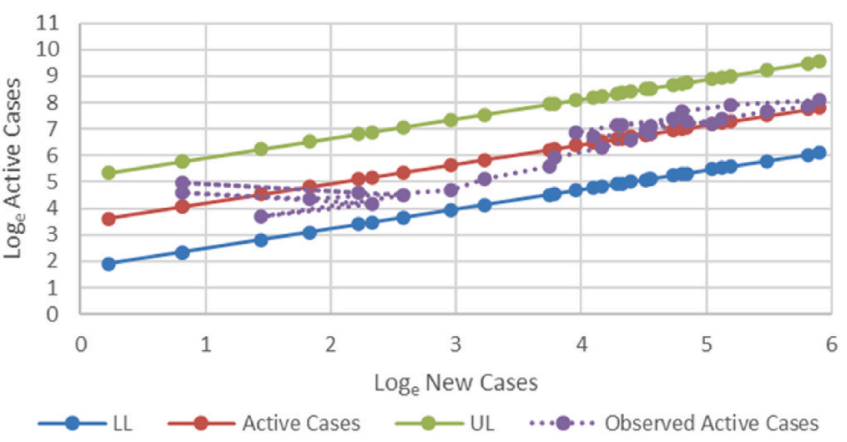

Fig. 15. Active cases by new cases in Chandigarh

Active cases by new cases in Ladakh

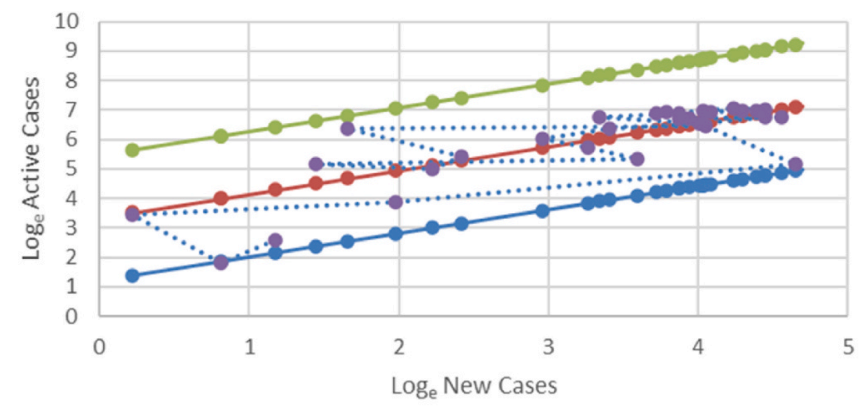

$\longrightarrow$ LL $\longrightarrow$ Active Cases $\longrightarrow$ UL $\quad$... $\bullet$.. Observed Active Cases

Fig. 16. Active cases by new cases in Ladakh

respectively (Table 1).

\subsection{Northern region}

In the northern region, log of new cases against log of predicted active cases was plotted with the corresponding upper and lower confidence limits for the states Rajasthan, Jammu and Kashmir, Himachal Pradesh, Uttarakhand, Haryana, Delhi, Punjab, Chandigarh, and Ladakh and were found to be linear (Figs. 8-16). The average duration of days in Rajasthan $\left(\mathrm{R}^{2}=0.93\right)$ and Jammu Kashmir $\left(\mathrm{R}^{2}=0.93\right)$ is 14 days $(\mathrm{CI}=$ 11.80-16.98) (CI = 11.33-16.11), Himachal Pradesh $\left(R^{2}=0.91\right)$ takes around 18 days $(\mathrm{CI}=15.93-21.30)$ while Uttarakhand $\left(\mathrm{R}^{2}=0.90\right)$ takes around 20 days $(\mathrm{CI}=116.62-23.61)$ followed by Haryana $\left(\mathrm{R}^{2}=0.89\right)$ 31 days $(\mathrm{CI}=25.56-38.02)$ and Chandigarh $\left(\mathrm{R}^{2}=0.78\right) 32$ days $(\mathrm{CI}=$

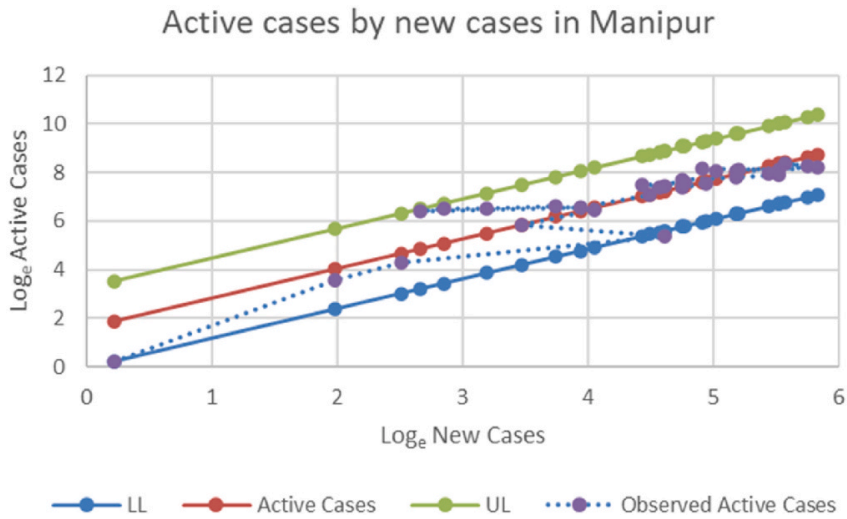

Fig. 17. Active cases by new cases in Manipur

Active cases by new cases in Arunachal Pradesh

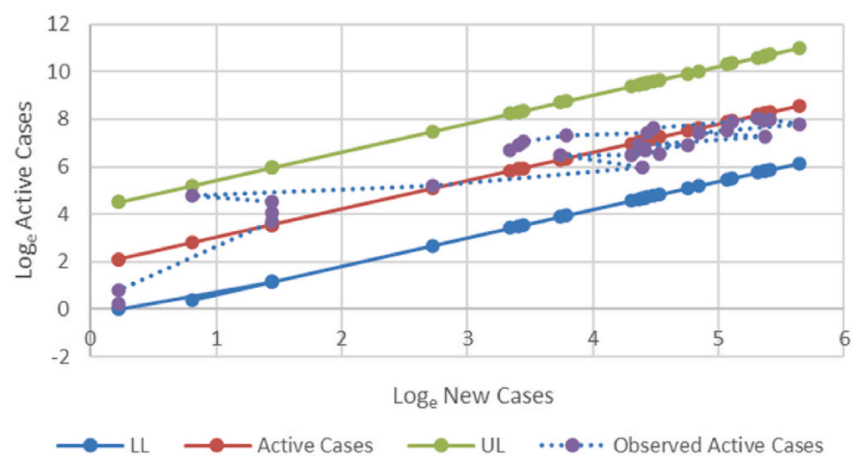

Fig. 18. Active cases by new cases in Arunachal Pradesh

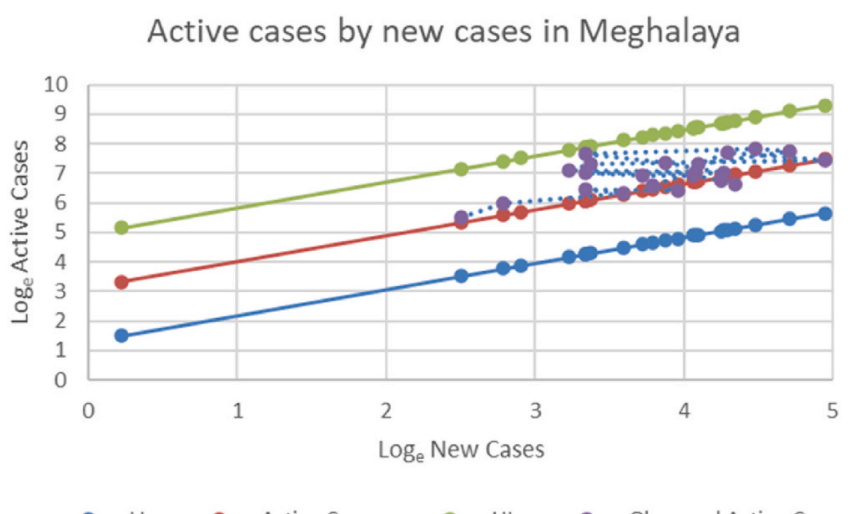

Fig. 19. Active cases by new cases in Meghalaya

26.83-37.50). With an average length of 36 days, Punjab $\left(R^{2}=0.8\right)$ has the highest recovery rate among the northern states $(\mathrm{CI}=28.37-48.04)$. Delhi $\left(\mathrm{R}^{2}=0.87\right)$ has an average recovery time of 22 days, having a confidence interval of 17 days-30 days. The union territories like Ladakh $\left(R^{2}=0.75\right)$, which has a model fit of $75 \%\left(R^{2}=0.75\right)$ and has an average recovery duration of 28 days (CI $=23.76-33.32)$ (Table 1 ).

\subsection{Northeastern region}

Log of new cases against log of predicted active cases with the upper and lower confidence limits was plotted for northeast states, including Manipur, Arunachal Pradesh, Meghalaya, Assam, Nagaland, Sikkim, and Mizoram (Figs. 17-22). High model fit was found in states of Manipur 
Active cases by new cases in Assam

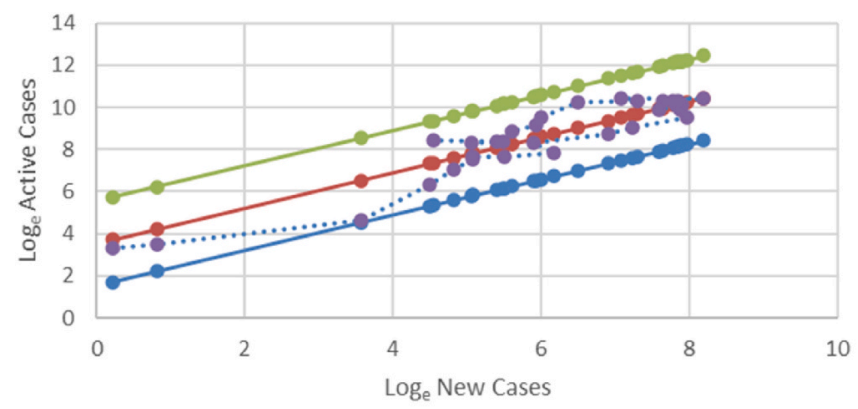

$\longrightarrow \mathrm{LL} \longrightarrow$ Active Cases $\longrightarrow$ UL $\longrightarrow$... Observed Active Cases

Fig. 20. Active cases by new cases in Assam

Active case by new cases in Nagaland

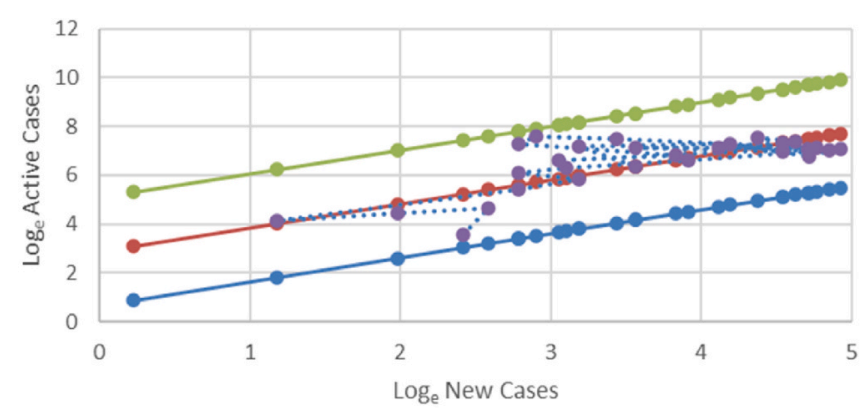

$\longrightarrow \mathrm{LL} \longrightarrow$ Active Cases $\longrightarrow$ UL $\quad . . \cdot$.. Observed Active Cases

Fig. 21. Active cases by new cases in Nagaland

Active cases by new cases in Sikkim

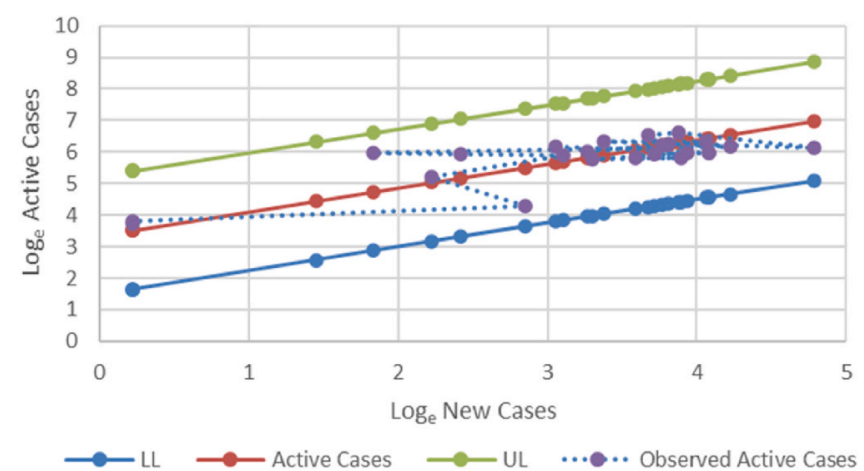

Fig. 22. Active cases by new cases in Sikkim

$\left(\mathrm{R}^{2}=0.93\right)$, Arunachal Pradesh $\left(\mathrm{R}^{2}=0.86\right)$, Meghalaya $\left(\mathrm{R}^{2}=0.85\right)$ and Assam $\left(R^{2}=0.85\right)$ with average recovery days of $5,6,23,34$ days (Table 1). Nagaland $\left(\mathrm{R}^{2}=0.67\right)$ has a model fit of $67 \%\left(\mathrm{R}^{2}=0.67\right)$ and has a duration of 18 days $(\mathrm{CI}=12.4-24.9)$, similarly Sikkim $\left(\mathrm{R}^{2}=0.66\right)$ with a model fit of $67 \%\left(\mathrm{R}^{2}=0.67\right)$ and duration of 29 days $(\mathrm{CI}=$ 22.84-35.76). Finally, Mizoram $\left(\mathrm{R}^{2}=0.58\right.$ ) has the least model fit with $59 \%\left(\mathrm{R}^{2}=0.59\right)$ and a duration of 16 days $(\mathrm{CI}=12.20-19.78)$ (Table 1$)$.

\subsection{Southern region}

For southern states named Tamil Nadu, Karnataka, Kerala, Andhra Pradesh, with the union territories of Puducherry, and Andaman and
Active cases by new cases in Tamil Nadu

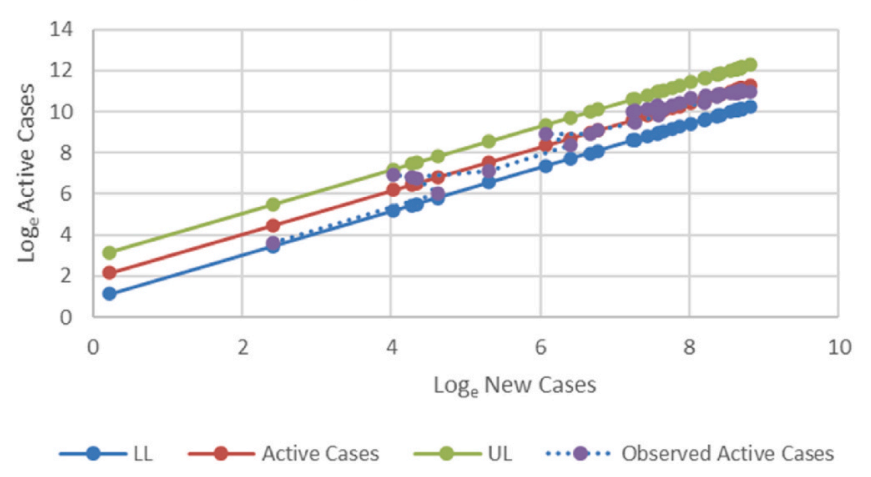

Fig. 23. Active cases by new cases in Tamil Nadu

Active cases by new cases in Karnataka

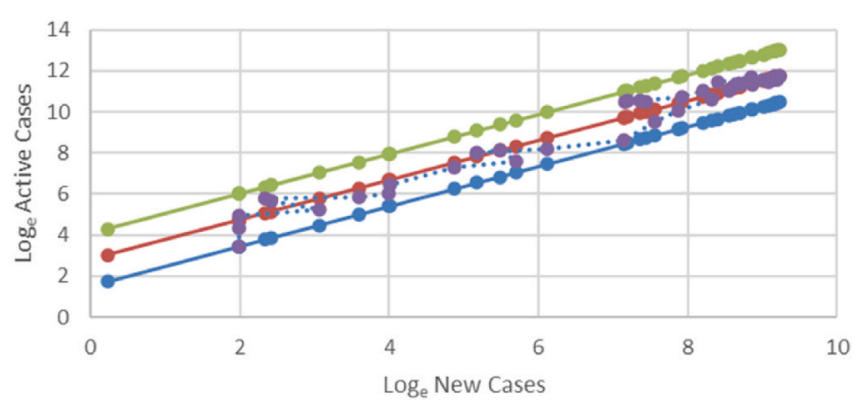

$\longrightarrow \mathrm{LL} \longrightarrow$ Active Cases $\longrightarrow$ UL $\cdots \bullet$. Observed Active Cases

Fig. 24. Active cases by new cases in Karnataka

Active cases by new cases in Kerala

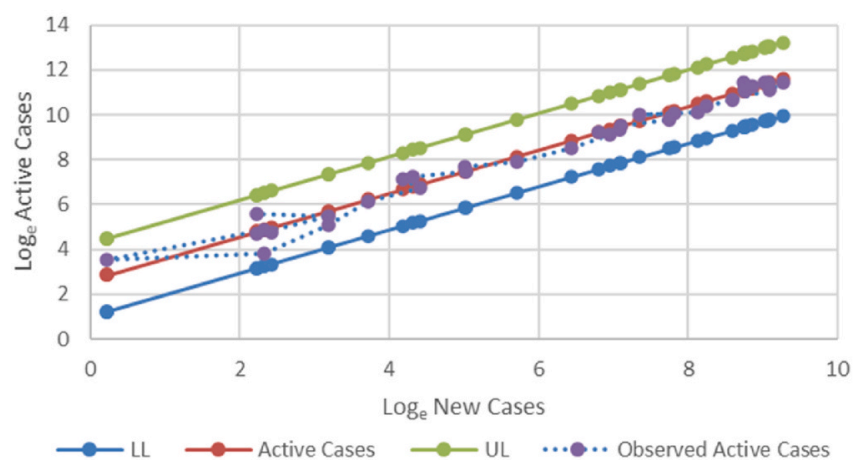

Fig. 25. Active cases by new cases in Kerala

Nicobar Islands, log of new cases against log of predicted active cases with the upper and lower confidence limits were plotted (Figs. 23-28). Andhra Pradesh $\left(\mathrm{R}^{2}=0.89\right)$ takes an average of 19 days $(\mathrm{CI}=$ 14.61-24.47, 15.64-22.67) to recover, where Andaman and Nicobar Islands $\left(\mathrm{R}^{2}=0.8\right)$ and Tamil Nadu $\left(\mathrm{R}^{2}=0.96\right)$ take an average of 7 days $(\mathrm{CI}=5.99-8.53,5.71-7.99)$ to recover, followed by Kerala $\left(\mathrm{R}^{2}=0.94\right)$ with 14 days $(\mathrm{CI}=11.88-16.17)$, Karnataka $\left(\mathrm{R}^{2}=0.95\right)$ with 17 days $(\mathrm{CI}=13.75-19.82)$, and Puducherry $\left(\mathrm{R}^{2}=0.82\right)$ with 23 days $(\mathrm{CI}=$ 18.74-28.08) (Table 1).

\subsection{Western region}

In western states, Gujarat, Goa, Maharashtra Dadra, Nagar Haveli, Daman and Diu, log new cases against log predicted active cases along 
Active cases by new cases in Andhra Pradesh

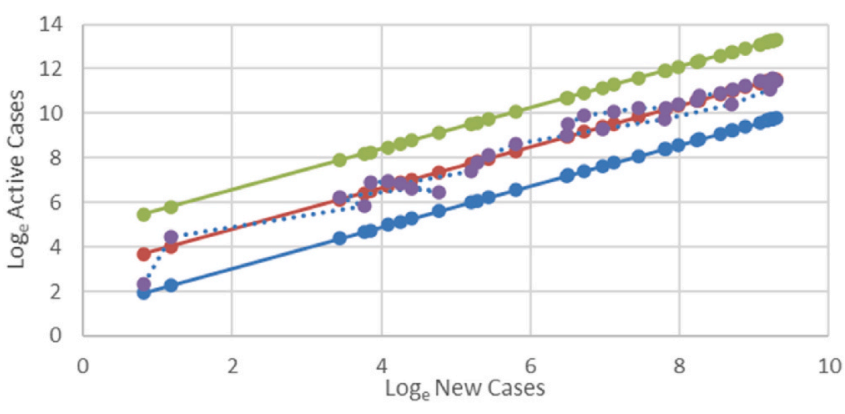

$\longrightarrow \mathrm{LL} \longrightarrow$ Active Cases $\longrightarrow$ UL $\cdots \bullet$. Observed Active Cases

Fig. 26. Active cases by new cases in Andhra Pradesh

Active casesby new cases in Puducherry

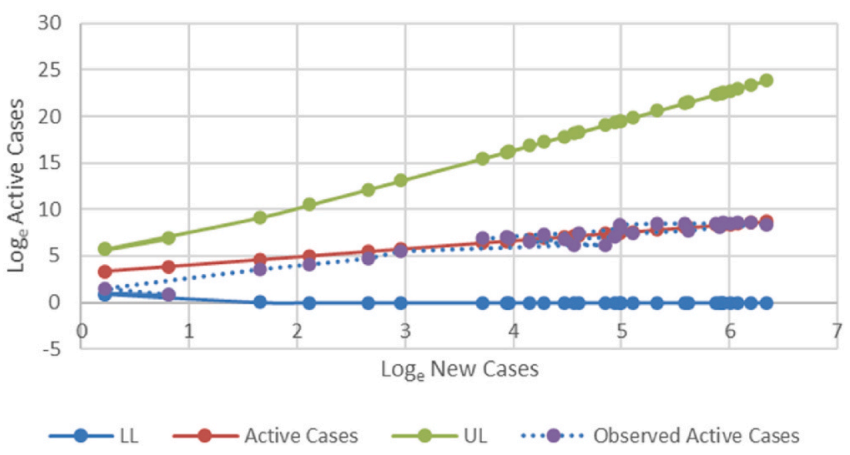

Fig. 27. Active cases by new cases in Puducherry

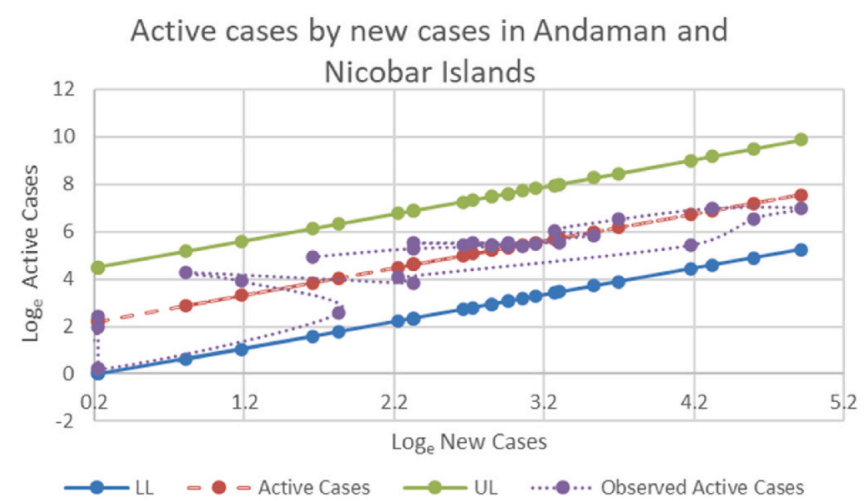

Fig. 28. Active cases by new cases in Andaman and Nicobar Islands

with its upper and lower confidence limits was plotted (Figs. 29-32). Dadra and Nagar Haveli and Daman and Diu $\left(\mathrm{R}^{2}=0.73\right)$ have a model fit of $73 \%\left(R^{2}=0.73\right)$ and have a duration of 15 days with a confidence interval of 12.44 days and 17.35 days wherein Goa $\left(\mathrm{R}^{2}=0.88\right)$ and Gujarat $\left(\mathrm{R}^{2}=0.92\right)$ the duration is almost equal, almost $8-10$ days $(\mathrm{CI}=$ $7.45-12.09,6.16-9.52)$. Maharashtra $\left(\mathrm{R}^{2}=0.86\right)$ has an average recovery time of 22 days, with a confidence interval of 15 days-32 days (Table 1).

\section{Discussion}

The model suited ideal for most states, some union territories and northeastern states considered to have a reduced fit in identifying the average time. The average time of recovery from the disease in India
Active cases by new cases in Gujarat

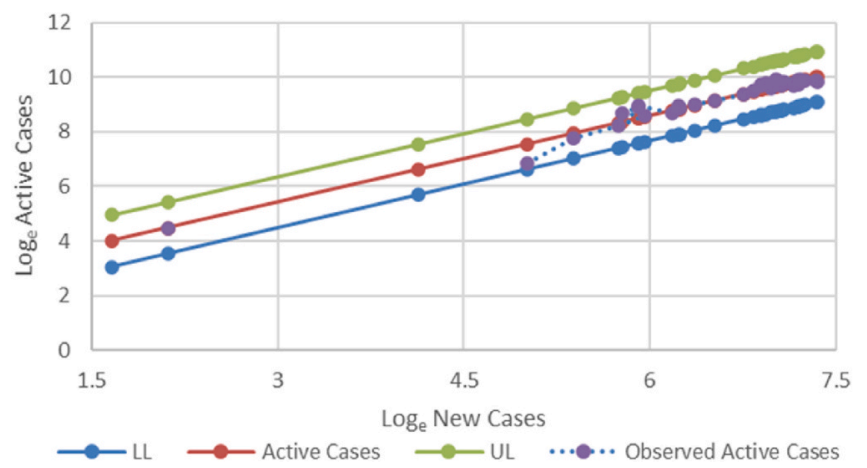

Fig. 29. Active cases by new cases in Gujarat

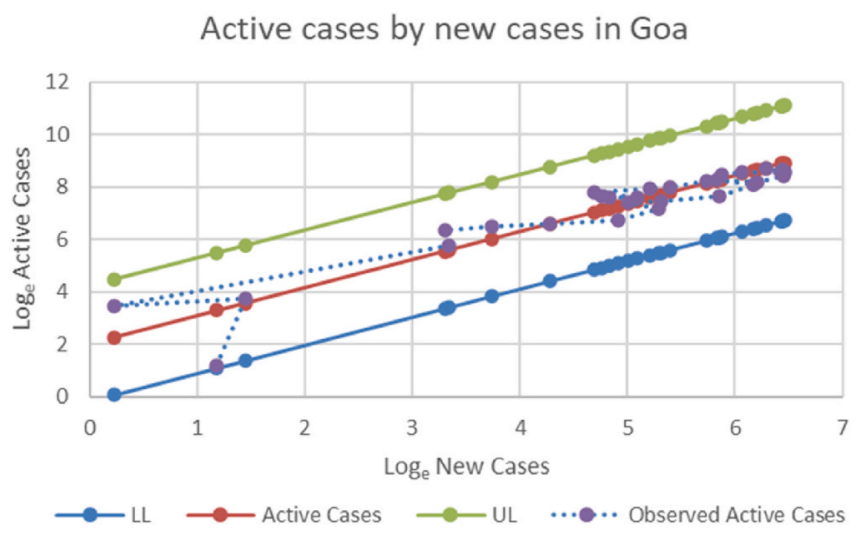

Fig. 30. Active cases by new cases in Goa

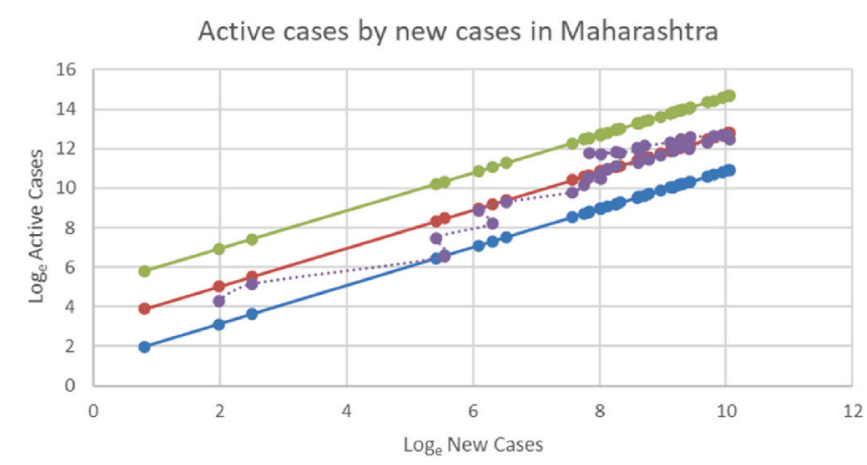

$\multimap \mathrm{LL} \longrightarrow$ Active Cases $\longrightarrow$ UL $\cdots \bullet \cdots$ Observed Active Cases

Fig. 31. Active cases by new cases in Maharashtra

ranges from 5 days to 68 days. However, Hospital studies by Manash et al. (2020) showed that COVID-19 patients in India have an estimated recovery time of 25 days ( $\mathrm{CI}=16$ days -34 days). The recovery period estimated for male and female patients and patients belonging to different age groups is also not statistically significant. ${ }^{9}$ The rigorous proof for the relation between age-independent incidence, prevalence and time duration was initially provided by Keiding (1991). Miettinen (1976), Freeman and Hutchison (1980) had earlier presented heuristic derivations for the same special case. A related identity has also been proven by Keiding (1991) (see Freeman and Hutchison, 1980, p. 709). The relationships between time period and cohort measures under general growth were addressed by Preston (1987). ${ }^{3}$ The relationship between prevalence, incidence, and disease duration is studied in a 


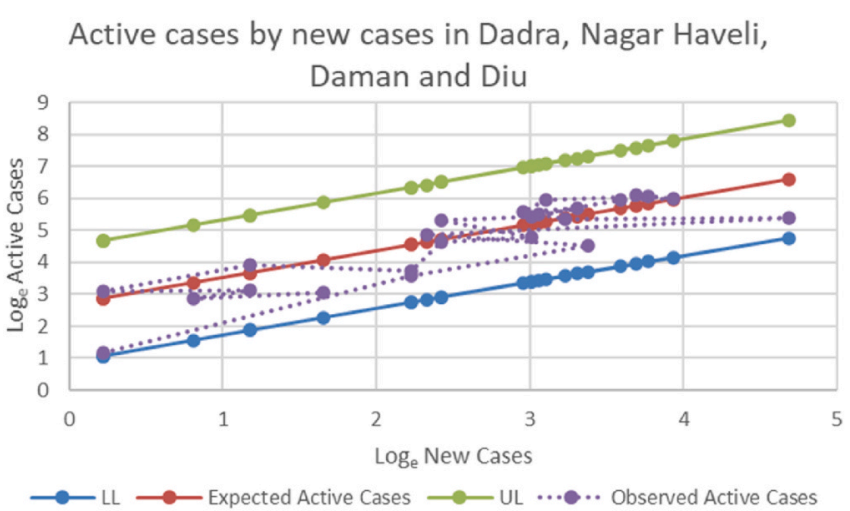

Fig. 32. Active cases by new cases in Dandra, Nagar Haveli, Daman and Diu

linear relationship for a stable population. The nationwide lockdown due to COVID-19 has produced the closed population's situation where migration is considered negligible. ${ }^{4}$ The average recovery time in Madhya Pradesh (approx. 68 days) and Manipur (approx. 5 days) was found to be outliers when compared with other states in India. As per Lancet, Madhya Pradesh and Telangana found a high overall vulnerability (index value more than 0.75 ) for the management of and response to the COVID-19. ${ }^{8}$

In India, the first positive case was registered in Kerala on January 27, 2020; however, the first case of COVID-19 in North East India was found precisely in Manipur, which was a bit late compared to other regions of India. ${ }^{15}$ Studies showed that Assam and Meghalaya had a very low potential compared to Tripura in controlling the present pandemic situation. A moderate potentiality to control the situation was found in Arunachal Pradesh and Nagaland. Sikkim and Mizoram have a very high potentiality than Manipur to control COVID-19. ${ }^{16}$ In this study, the model fits best for the states of Manipur, Arunachal Pradesh, Meghalaya and Assam, with average recovery days of 5, 6, 23, 34 days correspondingly and reduced fit for Nagaland with 18 days, Sikkim with 29 days. Mizoram has the least fit and an average duration of 16 days.

On the west side of India, Dadra and Nagar Haveli and Daman and Diu have the least model fit and have a duration of 15 days, whereas Gujarat, Goa, and Maharashtra have a high model fit the duration is almost equal, almost 9, 7, and 22 days correspondingly. Testing in the Union territories became functional only on April 6, 2020, after which 23,023 samples have been tested to date January 21, 2021. Center explicitly enforced lockout, door-to-door survey and screening were scheduled, and 400 teams along with personnel from the Health and Education Department were dispatched to the field to perform comprehensive health screenings. ${ }^{6}$

The significant finding from the study by Kapil Ghosh et al.(2020) shows the inaccessibility of testing centres in the Eastern (Odisha, West Bengal, Bihar, and Jharkhand) Central and extreme Northern portion of India. ${ }^{17}$ The average duration of days where a patient remains in COVID-19 is approximately 11, 13, 17, 25 days in West Bengal, Odisha, Bihar, and Jharkhand. Every state in the eastern region has a good model fit. While central states like Chhattisgarh, Uttar Pradesh has a moderate fit with 12 and 25 average recovery days. Madhya Pradesh is considered as an outlier with a reduced fit and average recovery days of 68 . Assessing the northern region, the average duration of days in Rajasthan and Jammu Kashmir is 14 days; Himachal Pradesh takes around 18 days while Uttarakhand takes around 20 days, followed by Haryana 31 days and Chandigarh 32 days. The maximum duration taken by a state in the northern region is Punjab, with 36 days. The union territories like Ladakh, which has a reduced model fit and has an average duration of 28 days for a patient to be in the disease. Goel K et al. (2020) has studied and found that Srinagar-Leh highway opening and Iran pilgrimage returnees were the major challenges to estimate the actual data of COVID patients. The study also suggested that there is a need for a more robust surveillance system. ${ }^{5}$ Lockdown as restricting the migration of population and decision taken by the government to quarantine the population may greatly reduce the risk of continued spread of the epidemic in India. ${ }^{18}$ Towards the south, Andhra Pradesh takes approximately an average of 19 days to recover. Andaman and Nicobar Islands and Tamil Nadu takes an average of 7 days correspondingly for the recovery, followed by Kerala with 14 days, Karnataka with 17 days, and Puducherry 23 days.

\section{Conclusion}

Tamil Nadu was identified as the best fit for the model with an $\mathrm{R}^{2}$ value of 0.96, and Mizoram was identified to have the least fit with an $R^{2}$ value of 0.58 . At the same time, Manipur was identified to have the least average recovery duration with 4.94 days and the highest in Madhya Pradesh with 68 days. Despite the fact that the data was derived from government sources, the data quality and patient follow-up were not ensured by the database. Government and the hospitals' policies in admitting, fear in the community of getting admitted to a hospital and the healthcare workers' behaviour towards the COVID-19 patients, sensitivity and specificity of the diagnostic tests may also be some factors that could have caused the outlying in cases of Madhya Pradesh and Manipur. To an extent, the patients remaining in-home and migration in each state's population is identified as a limitation to the study. However, most of the states have different situations concerning COVID-19 and have unique problems to tackle, so it is preferred to consider these situations while comparing each state's average duration.

\section{Conflict of interest}

We hereby declare that the article entitled "COVID-19 pandemic and its average recovery time in Indian states" does not have any conflict of interest involved.

We also declared that this research article is nowhere submitted for publication.

\section{Ethical approval and consent to participate}

Not applicable.

\section{Availability of supporting data}

Open repository of Github.

\section{Funding}

No funding received.

\section{Declaration of competing interest}

The authors declare that they have no conflict of interest.

\section{References}

1 Rees EM, et al. COVID-19 length of hospital stay: a systematic review and data analysis, 18 https://doi.org/10.1186/s12916-020-01726-3; 2020, 270.

2 Lauer SA, et al. The incubation period of coronavirus disease 2019 (COVID-19) from publicly reported confirmed cases: estimation and application. Ann Intern Med. 2020; 172(9):577-582. https://doi.org/10.7326/M20-0504.

3 Alho JM. On prevalence, incidence, and duration in general stable population. Biometrika. 1992;48(2):587-592. https://doi.org/10.2307/2532312.

4 Kumar R, Mishra RS. Estimation of COVID - 19 prevalence under closed population using capture - recapture approach. Int J Sci Res. 2020;9(7):451-457. https://doi. org/10.21275/SR20629043404, 2020.

5 Goel K, et al. The successful containment of COVID-19 outbreak in Union Territory of Ladakh, India. J Fam Med Prim Care. 2021;9(11):5574-5579. https://doi.org/ 10.4103/jfmpc.jfmpc_1413_20.

6 http://www.businessworld.in/article/COVID-19-Daman-Diu-And-Dadra-NagarHaveli-Script-A-Mini-Success-Story/16-06-2020-287875/. 
7 Khan Q, Swaminathan J. Impact of COVID-19 lockdown on mental health and social life of university students of Delhi. Int J Health Sci Res. 2020;10(12):222-230.

8 Acharya R, Porwal A. A vulnerability index for the management of and response to the COVID-19 epidemic in India: an ecology study. Lancet. 2020;8(9):1142-1151. https://doi.org/10.1016/S2214-109X(20)30300-4.

9 Barman MP, Rahman T, Bora K, Borgohain C. COVID-19 pandemic and its y time of patients in India: a pilot study, Diabetes \& Metabolic Syndrome. Clin Res Rev. 2020. https://doi.org/10.1016/j.dsx.2020.07.004.

10 Keiding N. Age-specific incidence and prevalence: a statistical perspective. J Roy Stat Soc. 1991; Series A 154:371-412.

11 Miettinen OS. Estimability and estimation in case-referent studies. Am J Epidemiol. 1976;103:226-235.

12 Freeman J, Hutchison GB. Prevalence, incidence, and duration. Am J Epidemiol. 1980;112:707-723.

13 Preston SH. Relations among standard epidemiologic measures in a population. Am J Epidemiol. 1987;126:336-345.
14 Chatterjee Patralekha. Is India missing COVID-19 deaths? Lancet. 2020;396(10252). https://doi.org/10.1016/S0140-6736(20)31857-2. Page 657, ISSN 0140-6736.

15 Ghosh P, Ghosh R, Chakraborty B. COVID-19 in India: statewise analysis and prediction. JMIR public health and surveillance. 2020;6(3), e20341. https://doi.org/ $10.2196 / 20341$.

16 Mahato R, Bushi D, Nimasow G. AHP and GIS-based risk zonation of COVID-19 in North East India. Curr World Environ. 2020;15(3). https://doi.org/10.12944/ CWE.15.3.29.

17 Ghosh Kapil, Sengupta Nairita, Manna Dipanwita, Sunil Kumar De. Inter-state transmission potential and vulnerability of COVID-19 in India. Progress in Disaster Science. 2020;7. https://doi.org/10.1016/j.pdisas.2020.100114, 100114,ISSN 25900617.

18 Bhattacharjee Atanu, Kumar Mukesh, Patel Kamalesh Kumar. When COVID-19 will decline in India? Prediction by combination of recovery and case load rate. Clinical Epidemiology and Global Health. 2021;9:17-20. https://doi.org/10.1016/j. cegh.2020.06.004. ISSN 2213-3984. 